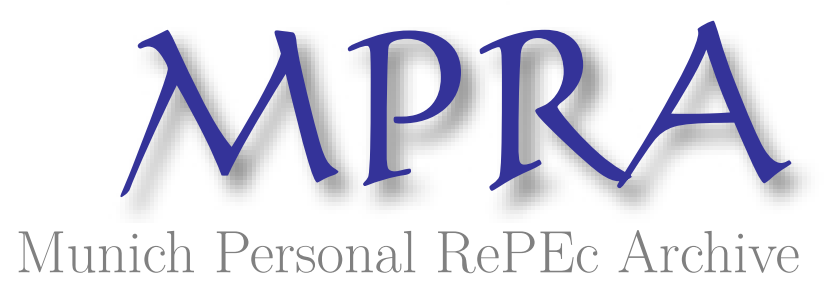

\title{
Should the optimal portfolio be region-specific? A multi-region model with monetary policy and asset price co-movements
}

Leung, Charles Ka Yui and Teo, Wing Leong

City University of Hong Kong, National Taiwan University

December 2010

Online at https://mpra.ub.uni-muenchen.de/28216/

MPRA Paper No. 28216, posted 19 Jan 2011 17:31 UTC 


\title{
Should the optimal portfolio be region-specific? A multi-region model with monetary policy and asset price co-movements*
}

\author{
Charles Ka Yui Leung ${ }^{\dagger}$ \\ Department of Economics and Finance \\ City University of Hong Kong \\ Hong Kong
}

\author{
Wing Leong Teo \\ Department of Economics \\ National Taiwan University \\ Taipei, Taiwan
}

December 30, 2010

\begin{abstract}
:
A multi-region, dynamic stochastic general equilibrium (MRDSGE) model is built to show that differences in the price elasticity of housing supply can be related to stylized facts on regional differences in (1) house price level, (2) house price volatility, (3) monetary policy propagation mechanism and (4) household asset portfolio. In addition, regional house prices are found to move more closely with regional fundamentals than with the national GDP. The correlation between the national stock price and the regional housing price also vary significantly across regions, which suggests that optimal portfolio should be region specific.

JEL Classification Numbers: E32, E52, R10, R33

Keywords: regional economic difference, monetary policy, housing market, region-specific portfolio.

${ }^{*}$ The authors are grateful to (alphabetical order) Richard Arnott, Erhan Artuc, Eric Hanushek, John Quigley, Tim Riddiough, Raven Saks, Sinan Sarpca, Ping Wang, Kuzey Yilmaz, seminar participants at the HKUST, Koc Conference, especially anonymous referees for comments and suggestions, and the City University of Hong Kong and National Taiwan University for their support. The work described in this paper was partially supported by a grant from the Research Grants Council of the Hong Kong Special Administrative Region, China [Project No. CityU 144709]. The usual disclaimer applies.

${ }^{\dagger}$ Department of Economics and Finance, The City University of Hong Kong, Kowloon Tong, Hong Kong SAR, China. Phone: (852) 2788-9604, Fax: (852) 2788-8806, Email: kycleung@cityu.edu.hk.

${ }_{\ddagger}^{\ddagger}$ Department of Economics, National Taiwan University, 21 Hsu Chow Road, Taipei 100, Taiwan. Phone: (886) 2351-9641-ext 449, Fax: (886) 2351-1826, Email: wlteo@ntu.edu.tw.
\end{abstract}




\section{Introduction}

Several striking stylized facts on regional economic differences are related to the real estate markets. First, even within the same country, tremendous differences in house prices are observed across regions. For instance, Hwang and Quigley (2006) show that for a sample of U.S. metropolitan areas (MSAs), during the period 1975-2000, the real prices of housing in three California housing markets had more than tripled, while the real housing prices in three other MSAs (Houston, Albany, and Oklahoma City) were stagnant. What accounts for such cross-sectional diversity becomes an important research topic. The empirical works of Glaeser, Gyourko and Saks (2005a, b), Hwang and Quigley (2006), among others, suggest that it is the local government regulation, such as "growth control" that limits the increase of housing supply and leads to a higher housing price at the equilibrium. Wheaton and Simonton (2007) find that "real construction costs have fallen slightly over the last 35 years," suggesting that house price increase is very unlikely to be driven by "cost-inflation." Recently, Saiz (2010) estimates the price elasticity of housing supply (henceforth, supply elasticity) and finds that variations across different metropolitan areas are very significant. ${ }^{1}$ For example, the supply elasticities in both Miami and Los Angeles-Long Beach are estimated to be below 0.7, the counterpart in Las Vegas is close to 1.4, while the supply elasticities in Kansas City and Oklahoma City are estimated to be well above 3.0. Saiz (2010) also finds that highly regulated metropolitan areas typically have low estimates of supply elasticities.

Not only the dramatic differences in the level of house prices can be attributed to the differences in the supply elasticities, the differences in the volatility of house prices may also be

\footnotetext{
${ }^{1}$ Green, Malpezzi and Mayo (2005) adopt a different methodology in estimating the price elasticity of housing supply. They also find that the variations across different metropolitan areas are in fact very large.
} 
explained by the differences in the supply elasticities. To show the relation between volatility of real house price and supply elasticity, we construct semi-annual real house price by dividing nominal housing price index from Case-Shiller (monthly data are averaged into semiannual data) by semi-annual city level CPI data from the BLS. ${ }^{2}$ We focus on semi-annual data because city-level CPIs are not available on a consistent basis for higher frequency. We choose the longest sample for which we can obtain the most data points, resulting in a sample from 1991S1-2010S1 (S here denotes semi-annual), yielding 39 data points for each of the 14 metropolitan areas we have data. The real house price is then logged and HP filtered with a smoothing parameter of 400 before standard deviation is calculated. The estimates of the supply elasticities are from Saiz (2010). Table 1 reports the data while Figure 1 provides a scatter-plot of the data together with the OLS regression line (red line). The slope of the regression line is $-3.6,{ }^{3}$ which is significant at $5 \%$. It shows that metropolitan areas with higher supply elasticities tend to have lower volatility of real house prices.

(Table 1 and Figure 1 about here)

The third stylized fact is that the monetary policy propagation mechanism varies across regions. For instance, Carlino and Defina (1998, 1999, 2006), among others, find significant heterogeneity in the income responses to monetary policy across different regions or states. In particular, they find (1) strong evidence that manufacturing-intensive states are more responsive to changes in monetary policy shocks than the more industrially diverse states, and (2) weaker evidence that states containing a relatively larger concentration of small

\footnotetext{
${ }^{2}$ The Case-Shiller index is available through http://www.standardandpoors.com/indices/sp-case-shillerhome-price-indices/en/us/?indexId=spusa-cashpidff-p-us - - . The Bureau of Labor Statistics data can be found in http://www.bls.gov/.

${ }^{3}$ Note that removing Atlanta (the outlier in terms of supply elasticity) will only make the slope of the regression line steeper.
} 
firms tend to be more responsive to monetary policy shifts than states composed of smaller concentrations of small firms. They also conclude that the evidence for a broad credit channel is weak. Fratantoni and Schuh (2003) construct a large VAR model in which the regional economic variables (regional house price, regional output, etc.) have potentially time-varying impact on the aggregate variables. The aggregate variables will then affect different regional variables simultaneously through the change in the mortgage rate, among other variables. They show that regional housing markets display heterogeneous responses to monetary policy shocks.

The fourth stylized fact is related to the apparently spatial-dependent household portfolio. For instance, Goetzmann, Massa and Simonov (2004) find that rural portfolios are more diversified than urban portfolios in their Swedish dataset. Moreover, the portfolio diversification of the agents in their sample seems to be characterized by factors associated with urban growth. Kohler and Smith (2005) find that in the Australian data, with a 100 person per square kilometer increase in urbanization, the portfolio share of home will increase by 0.4 percentage points on average.

While there may be different explanations for each of these stylized facts, this paper attempts to study these facts in a unifying framework by extending a standard dynamic stochastic general equilibrium (DSGE) model to a multi-regional setting. While the previous literature focuses on the fiscal policy competition or coordination among regions, ${ }^{4}$ this paper is devoted to study the regional housing markets and their interactions with the monetary policy in a multi-regional setting. ${ }^{5}$ A merit of DSGE model is that both the quantity variables (such as consumption and investment) and price variables (such as non-durable goods price, housing price and stock price) are all endogenously determined. All agents maximize their objective functions in the model. Thus, it is easier to understand the transmission mechanism

\footnotetext{
${ }^{4}$ The literature is too large to be reviewed here. Among others, see the survey papers by Epple and Nechyba (2004).

${ }^{5}$ To the best of our knowledge, it seems that this paper is the first paper which combines the nominal rigidities and the regional consideration in a DSGE framework. Among others, see Leung (2004).
} 
of the monetary policy.

To highlight the role of the housing market in the aggregate economy as well as the financial market, we assume that the two regions are ex-ante identical except that the housing adjustment costs differ across regions. Without loss of generality, the adjustment cost is assumed to be lower in the region $1 .^{6}$ The two regions will then be subject to region-specific shocks. In this model as in practice, history dependent contingent claims are not available. Fortunately, there is a national stock market which (1) "owns" the firms in both regions, and (2) welcomes investment of agents from different regions. ${ }^{7}$ The housing market, however, is "regional." In particular, we assume that the agents in each region can only purchase and derive utility from the housing stock in the same region. ${ }^{8}$

For monetary policy to have any real effects, we introduce nominal rigidity in the goods market. Following Calvo (1983), the renewal of nominal price contracts are random (which will be explained in more details later). To facilitate the comparison with the literature, the government is restricted to follow the Taylor rule (Taylor, 1993). In words, it means that the monetary authority will respond to the fluctuations of the inflation rate and the GDP. Taylor (1993) and many subsequent writers find that the Taylor rule is a good (first-order) approximation of the monetary policy that has been practiced.

To focus on the business cycle effect, the regions in the model are assumed to have the same (long run) economic growth rate, which is then normalized to zero. While it might seem to be a strong assumption in the first glance, it may nevertheless be consistent with

\footnotetext{
${ }^{6}$ The difference in adjustment costs need not be due to physical or engineering reason, but due to political economy reason. Among others, Ortalo-Magne and Prat (2007) build a political economy model in which the equilibrium housing supply can be inefficiently low, as homeowners try to protect their interests. This paper attempts to focus on the aggregate implications for such difference and will therefore take the difference as given.

${ }^{7}$ In principle, as one referee wisely observes, since history-dependent contingent claims are not available, the paths of the equilibrium price and quantities can be history dependent. In our numerical implementations, since we focus on the moments over a sample period rather than the exact time paths, we do not observe significant changes in results with different initial conditions.

${ }^{8}$ While this assumption will preclude the fact that some people in the North own seasonal homes in the South, say Florida, it seems that the assumption is very realistic for most of the population in the USA.
} 
some empirical research. ${ }^{9}$ To further simplify the analysis, we also assume that the agents will not move across regions. ${ }^{10}$

Clearly, this paper builds on a large literature on monetary policy. ${ }^{11}$ This paper complements the literature by explicitly considering different regions in a DSGE model. This enables us to differentiate the assets into two classes: national assets called "stock" and "bonds," and a regional one called "housing." Thus, this paper also introduces a "regional aspect" into the standard general equilibrium asset pricing literature, such as Jermann (1998, 2002, 2006). As it will become clear, the behavior of the national housing price (index) can behave very differently from the regional counterpart. An important implication, which we will discuss further, is that the optimal portfolio of agents from different regions can be very different.

After the first draft of this paper has been presented in conferences, we become aware of Ortalo-Magne and Prat (2007). They intend to provide a micro-foundation for the difference in the supply elasticity based on a political economy model. This paper instead attempts to relate stylized facts concerning the city-level house prices to the corresponding supply elasticities. In particular, this paper shows that the difference in the supply elasticity does not only contribute to the differences in the levels and volatilities of the house prices, it can also lead to difference in the agents portfolio as well as difference in the monetary policy propagation mechanism across regions. Thus, the two papers have very different focuses and should be viewed as complementary to each other.

The organization of this paper is as follows. The next section presents the model. Section

\footnotetext{
${ }^{9}$ For instance, after reviewing a large empirical literature on the regional convergence, Evans (2000) concludes that "the per capita incomes of the contiguous U.S. states show a pronounced tendency to converge toward parallel balanced growth paths. Furthermore, the convergence is rapid on average, even though the estimated convergence rates are widely dispersed across the states and quite imprecisely estimated for each individual state."

${ }^{10}$ Allowing agents to move across regions in a dynamic general equilibrium setting could lead to very complicated dynamics, which are difficult to calibrate numerically. Among others, see Berliant and Kung (2009).

${ }^{11}$ The literature is too large to be reviewed here. Among others, see Christiano, Trabandt and Walentin (2010) and Woodford (2010) for a survey of the literature.
} 
3 discusses solution method and calibration issues. Numerical results are presented in Section 4. The last section concludes.

\section{The model}

This section presents a closed economy model with two regions, called region 1 and region 2 . Time is discrete and the horizon is infinite. There are several agents in this model economy. In each region, there is a representative household which provides labor services and consumes non-durable goods as well as housing services in each period. The population of region $i$ is $n_{i}$, $i=1,2$, and is assumed to be fixed. Without loss of generality, we assume that $n_{2}=1-n_{1}$, and sometimes write $n_{1}=n$ to ease the burden of notations. The consumption goods are a constant elasticity of substitution composite of goods from the two regions. Goods from the two regions are in turn composite of many differentiated products, each provided by a monopolistically competitive firm. Each firm hires labor and rents the business capital from the representative household, and combines them to produce goods. The consolidated government conducts monetary policy using a Taylor-style interest rate feedback rule.

The adjustments of prices are staggered à la Calvo (1983). In order to facilitate comparison with the recent literature, we focus on the Woodford (2003) case of a "cashless" economy. ${ }^{12}$ We also assume that the government always balances the budget by making lump sum transfer, so that there is no fiscal policy consideration. Unless otherwise specified, the two regions are assumed to be symmetric, sharing the same structural parameters. To simplify the exposition, we will focus on the description of region 1. Region 2 variables will be denoted by asterisks.

\footnotetext{
${ }^{12}$ As explained in Woodford (2003), the "cashless" economy is similar to a setup where money demand is introduced by adding a real money balance term in the utility that is separable from consumption and leisure.
} 


\subsection{Final goods production}

Each region is assumed to produce a final good that is not traded across regions. The production function for final goods in region $1, Z_{t}$, is:

$$
Z_{t}=\left[(\varpi)^{\frac{1}{\varrho}}\left(Q_{1, t}\right)^{\frac{\rho-1}{\varrho}}+(1-\varpi)^{\frac{1}{\varrho}}\left(Q_{2, t}\right)^{\frac{\rho-1}{\varrho}}\right]^{\frac{\rho}{\rho-1}},
$$

where $Q_{1, t}$ and $Q_{2, t}$ are goods from region 1 and region 2, respectively. By the same token, there is another production function for final goods in region $2, Z_{t}^{*}$,

$$
Z_{t}^{*}=\left[\left(\varpi^{*}\right)^{\frac{1}{\varrho}}\left(Q_{1, t}^{*}\right)^{\frac{\varrho-1}{\varrho}}+\left(1-\varpi^{*}\right)^{\frac{1}{\varrho}}\left(Q_{2, t}^{*}\right)^{\frac{\rho-1}{\varrho}}\right]^{\frac{\varrho}{\varrho-1}}
$$

where $Q_{1, t}^{*}$ and $Q_{2, t}^{*}$ are goods from region 1 and region 2 , respectively. The parameter $\varpi \in$ $(0,1)$ determines the share of $Q_{1, t}$ in the final goods of region 1 in the steady state. To allow for home-biasedness in the regional composition of final goods, the corresponding parameter for the final goods of region 2 will be denoted by $\varpi^{*}$, with $\varpi^{*}$ potentially different from $\varpi .{ }^{13}$ To ensure that (1) and (2) are symmetric, we need the condition that $\varpi=\left(1-\varpi^{*}\right)$. In addition, the home-biasedness in the composition of final goods implies that $\varpi>0.5>\varpi^{*}$. $\varrho>0$ is the elasticity of substitution between $Q_{1, t}$ and $Q_{2, t}$. The goods $Q_{1, t}$ and $Q_{2, t}$ are a Dixit-Stiglitz aggregation of intermediate goods from region 1 and region 2, respectively:

$$
\begin{gathered}
Q_{1, t}=\left[\left(\frac{1}{n}\right)^{\frac{1}{\eta_{y}}} \int_{0}^{n}\left(Q_{1, t}(i)\right)^{\frac{\eta_{y}-1}{\eta_{y}}} d i\right]^{\frac{\eta_{y}}{\eta_{y}-1}}, \\
Q_{2, t}=\left[\left(\frac{1}{1-n}\right)^{\frac{1}{\eta_{y}}} \int_{1-n}^{1}\left(Q_{2, t}(i)\right)^{\frac{\eta_{y}-1}{\eta_{y}}} d i\right]^{\frac{\eta_{y}}{\eta_{y}-1}},
\end{gathered}
$$

\footnotetext{
${ }^{13}$ Clearly, it is beyond the scope to review the literature on "home-biasedness" in this paper. Among others, see Tesar (1993), Tesar and Werner (1995), Baxter, Jermann and King (1998), Jermann (2002).
} 
where $Q_{1, t}(i)$ and $Q_{2, t}(i)$ are brand $i$ goods from regions 1 and 2 , respectively. Implicitly, we have assumed that the measure of differentiated product brands in each region is proportional to the corresponding population size. Thus, when $n \longrightarrow 1$, the current two-region model will collapse into a typical closed economy macroeconomic model. $\eta_{y}>1$ is the elasticity of substitution across different varieties of goods. Cost minimization implies the following demand functions:

$$
\begin{gathered}
Q_{1, t}(i)=\frac{1}{n}\left(\frac{\boldsymbol{P}_{1, t}(i)}{\boldsymbol{P}_{1, t}}\right)^{-\eta_{y}} Q_{1, t}, \\
Q_{2, t}(i)=\frac{1}{1-n}\left(\frac{\boldsymbol{P}_{2, t}(i)}{\boldsymbol{P}_{2, t}}\right)^{-\eta_{y}} Q_{2, t}, \\
Q_{1, t}=\varpi\left(\frac{\boldsymbol{P}_{1, t}}{\boldsymbol{P}_{t}}\right)^{-\varrho} Z_{t}, \\
Q_{2, t}=(1-\varpi)\left(\frac{\boldsymbol{P}_{2, t}}{\boldsymbol{P}_{t}}\right)^{-\varrho} Z_{t},
\end{gathered}
$$

where $\boldsymbol{P}_{1, t}(i), \boldsymbol{P}_{2, t}(i)$, are (nominal) prices of brand $i$ goods from regions 1 and 2 that will be used to produce final goods in region 1 respectively, and $\boldsymbol{P}_{t}$ is the general price level in region 1. Formally, $\boldsymbol{P}_{1, t}, \boldsymbol{P}_{2, t}$ and $\boldsymbol{P}_{t}$ are defined as follows:

$$
\begin{gathered}
\boldsymbol{P}_{1, t} \equiv\left[\frac{1}{n} \int_{0}^{n}\left(\boldsymbol{P}_{1, t}(i)\right)^{1-\eta_{y}} d i\right]^{\frac{1}{1-\eta_{y}}}, \\
\boldsymbol{P}_{2, t} \equiv\left[\frac{1}{1-n} \int_{1-n}^{1}\left(\boldsymbol{P}_{2, t}(i)\right)^{1-\eta_{y}} d i\right]^{\frac{1}{1-\eta_{y}}}, \\
\boldsymbol{P}_{t} \equiv\left[\varpi\left(\boldsymbol{P}_{1, t}\right)^{1-\varrho}+(1-\varpi)\left(\boldsymbol{P}_{2, t}\right)^{1-\varrho}\right]^{\frac{1}{1-\varrho}}
\end{gathered}
$$

Gross price inflation rate in region 1 can be defined as $\Pi_{t} \equiv \boldsymbol{P}_{t} / \boldsymbol{P}_{t-1}$. 


\subsection{Intermediate goods firms}

There is a continuum of monopolistically competitive firms in region 1 , indexed by $i \in[0, n]$. Firm $i$ 's production technology is given by:

$$
A_{t}\left(K_{t}(i)\right)^{\theta}\left(L_{t}(i)\right)^{1-\theta}
$$

where $K_{t}(i)$ and $L_{t}(i)$ are respectively the amounts of capital and labor input used by firm i. $\theta \geq 0$ is the share of capital. $A_{t}$ is the aggregate technology process for region 1 , which evolves according to the law of motion:

$$
\ln A_{t}=\rho^{A} \ln A_{t-1}+\varepsilon_{t}^{A}
$$

where $\rho^{A} \in(0,1)$ is the first order autoregressive parameter and $\varepsilon_{t}^{A}$ is an i.i.d. shock with standard deviation, $\sigma_{\varepsilon^{A}}$. There is a parallel structure in the region 2 . The firms there are subjected to another technology shock $A_{t}^{*}$, following a law of motion similar to (12). For simplicity and as a preliminary step in introducing regional considerations in a DSGE model, we assume that the two region shocks are independent. The existence of these region-specific shocks has been found to be very important, especially to the housing market. ${ }^{14}$

The demand for intermediate goods $i, Y_{t}(i)$ comes from regions 1 and 2 :

$$
\begin{aligned}
Y_{t}(i) & =Q_{1, t}(i)+Q_{1, t}^{*}(i), \\
& =\frac{1}{n}\left(\frac{\boldsymbol{P}_{1, t}(i)}{\boldsymbol{P}_{1, t}}\right)^{-\eta_{y}} Y_{t}
\end{aligned}
$$

where $Y_{t}$ is given by:

$$
Y_{t}=Q_{1, t}+Q_{1, t}^{*}
$$

\footnotetext{
${ }^{14}$ The empirical literature on national versus regional shock is too large to be reviewed here. Among others, see $\mathrm{Fu}$ (2007) for some recent results and a review of the literature.
} 
$Y_{t}^{*}$ is defined similarly, $Y_{t}^{*}=Q_{2, t}+Q_{2, t}^{*}$. Since the steady state relative price of the output in the two regions is unity, the real national GDP is simply the sum of the output in the two regions, $Y_{t}+Y_{t}^{*}$.

Firm $i$ chooses $K_{t}(i)$, and $L_{t}(i)$ by minimizing the cost of production subject to the constraint that the supply is able to meet the demand, $Y_{t}(i)$ :

$$
\begin{gathered}
\min R_{t}^{k} K_{t}(i)+\boldsymbol{W}_{t} L_{t}(i) \\
\text { s.t. } A_{t}\left(K_{t}(i)\right)^{\theta}\left(L_{t}(i)\right)^{1-\theta} \geq Y_{t}(i),
\end{gathered}
$$

where $R_{t}^{k}$ and $\boldsymbol{W}_{t}$ are nominal rental rate for capital and nominal wage rate, respectively. The first order conditions are:

$$
\begin{aligned}
R_{t}^{k} & =\theta M C_{t} A_{t}\left(K_{t}(i)\right)^{\theta-1}\left(L_{t}(i)\right)^{1-\theta}, \\
\boldsymbol{W}_{t} & =(1-\theta) M C_{t} A_{t}\left(K_{t}(i)\right)^{\theta}\left(L_{t}(i)\right)^{-\theta},
\end{aligned}
$$

where $M C_{t}$ denotes the Lagrangian multiplier associated with equation (16), and can be interpreted as the marginal cost. ${ }^{15}$

Following Calvo (1983), we assume that in each period, each firm has a random probability $\left(1-\alpha_{y}\right), \alpha_{y} \in(0,1)$ of resetting its nominal price, $\boldsymbol{P}_{1, t}(i)$. If $\boldsymbol{P}_{1, t}(i)$ is not reset, it is updated by the steady state regional general price inflation rate, $\Pi$ (which is the steady state value of $\left.\Pi_{t}\right)$, according to the rule $\boldsymbol{P}_{1, t}(i)=\Pi \boldsymbol{P}_{1, t-1}(i)$. Let $\tilde{\boldsymbol{P}}_{1, t}$ denote the new price that is reset in period $t$. After setting the price at period $t$, there is $\alpha_{y}^{\tau}$ probability that the nominal price has not been reset at period $t+\tau$, and hence $\boldsymbol{P}_{1, t+\tau}(i)=\Pi^{\tau} \tilde{\boldsymbol{P}}_{1, t}$. Making use of the price updating rule and the demand equation, (13), the price optimization problem for firm $i$ is:

\footnotetext{
${ }^{15}$ Given the structure of the model, marginal cost is equalized across firms, so there is no index $i$ on $M C_{t}$.
} 


$$
\max _{\tilde{\boldsymbol{P}}_{1, t}} E_{t} \sum_{\tau=0}^{\infty} \alpha_{y}^{\tau} \frac{\rho_{t, t+\tau}}{\boldsymbol{P}_{t+\tau}}\left[\pi^{\tau} \tilde{\boldsymbol{P}}_{1, t} \frac{1}{n}\left(\frac{\Pi^{\tau} \tilde{\boldsymbol{P}}_{1, t}}{\boldsymbol{P}_{1, t}}\right)^{-\eta_{y}} Y_{t+\tau}-T C\left(\frac{1}{n}\left(\frac{\Pi^{\tau} \tilde{\boldsymbol{P}}_{1, t}}{\boldsymbol{P}_{1, t}}\right)^{-\eta_{y}} Y_{t+\tau}\right)\right],
$$

where $\rho_{t, t+\tau}$ is a discount factor for profit. ${ }^{16} T C(\cdot)$ is the total cost as a function of output. The first order condition is:

$$
\tilde{\boldsymbol{P}}_{1, t}=\frac{\eta_{y}}{\eta_{y}-1} \frac{E_{t} \sum_{\tau=0}^{\infty}\left(\alpha_{y} \Pi^{-\eta_{y}}\right)^{\tau} \frac{\rho_{t, t+\tau}}{\boldsymbol{P}_{t+\tau}} M C_{t+\tau} \boldsymbol{P}_{1, t+\tau}^{\eta_{y}} Y_{t+\tau}}{E_{t} \sum_{\tau=0}^{\infty}\left(\alpha_{y} \Pi^{1-\eta_{y}}\right)^{\tau} \frac{\rho_{t, t+\tau}}{\boldsymbol{P}_{t+\tau}} \boldsymbol{P}_{1, t+\tau}^{\eta_{y}} Y_{t+\tau}} .
$$

While the formula may look complicated, the intuition is very simple. When a firm is offered an opportunity to optimally adjust the price, it will take into consideration that it may need to wait one period, or two periods, or three periods, and so on, with different probabilities attached to each possibility, before it can re-optimize the price again. Therefore, the firm needs to take into considerations all these different possibilities and sets a price at the current period which would maximize the expectation of the discounted profit.

\subsection{Household}

There is a representative household in each region. The representative household maximizes expected lifetime utility with period utility defined over consumption, $C_{t}$, labor hours, $L_{t}$ and housing service. To facilitate comparison with the previous literature, we follow Greenwood and Hercowitz (1991) to assume that the housing service in each period is proportional to the housing stock, $H_{t}$. The periodic utility function $u\left(C_{t}, H_{t}, L_{t}\right)$ is specified as separable in the three arguments:

$$
E_{0} \sum_{t=0}^{\infty} \beta^{t} u\left(C_{t}, H_{t}, L_{t}\right)
$$

\footnotetext{
${ }^{16} \rho_{t, t+\tau}=\beta^{\tau}\left(\Lambda_{t+\tau} P_{t+\tau}\right) /\left(\Lambda_{t} P_{t}\right)$ in equilibrium, where $\Lambda_{t}$ is given in equation (27).
} 


$$
u\left(C_{t}, H_{t}, L_{t}\right)=\frac{C_{t}^{1-\sigma}-1}{1-\sigma}+\gamma_{h} \frac{H_{t}^{1-\omega_{h}}-1}{1-\omega_{h}}-\gamma_{l} \frac{L_{t}^{1+\xi}}{1+\xi}
$$

where $E_{t}$ is the expectations operator conditional on period $t$ information, $\beta \in(0,1)$ is the subjective discount factor, $\sigma, \omega_{h}>0$ are the coefficients of relative risk aversion for consumption and housing services, respectively, $\xi \geq 0$ is the inverse of Frisch labor supply elasticity, and $\gamma_{l}, \gamma_{h}>0$ are preference parameters. When $\sigma=\omega_{h}=\xi=1$, the periodic utility function will be reduced to a "semi-log" form, ${ }^{17}$

$$
u\left(C_{t}, H_{t}, L_{t}\right)=\ln C_{t}+\gamma_{h} \ln H_{t}-\left(\gamma_{l} / 2\right)\left(L_{t}\right)^{2} .
$$

The representative household owns business capital, $K_{t}$, and housing stock, $H_{t}$, which evolve according to the laws of motion:

$$
\begin{gathered}
K_{t+1}=\left(1-\delta_{k}\right) K_{t}+I_{k, t}-\frac{\phi_{k}}{2} \frac{\left(K_{t+1}-K_{t}\right)^{2}}{K_{t}}, \\
H_{t+1}=\left(1-\delta_{h}\right)\left(H_{t}+H_{t}^{m}\right)+I_{h, t}-\frac{\phi_{h}}{2} \frac{\left(H_{t+1}-\left(H_{t}+H_{t}^{m}\right)\right)^{2}}{H_{t}+H_{t}^{m}},
\end{gathered}
$$

where $I_{k, t}$ and $I_{h, t}$ are the gross capital and housing investments, respectively. $H_{t}^{m}$ is the amount of housing stock directly purchased from the market. $\frac{\phi_{k}}{2} \frac{\left(K_{t+1}-K_{t}\right)^{2}}{K_{t}}$ and $\frac{\phi_{h}}{2} \frac{\left(H_{t+1}-\left(H_{t}+H_{t}^{m}\right)\right)^{2}}{H_{t}+H_{t}^{m}}$, with $\phi_{k}, \phi_{h}>0$, are quadratic capital adjustment costs. We assume that the housing adjustment cost parameter for region $2, \phi_{h}^{*}$, might differ from that of region $1 . \delta_{k}, \delta_{h} \in(0,1)$ are the depreciation rates of capital and housing stock.

The period-by-period budget constraint (in nominal terms) of the representative house-

\footnotetext{
${ }^{17}$ Clearly, log utility has been widely used in the literature. Setting $\xi=1$ is not uncommon in the literature. Among others, see Christiano et al. (2005).
} 
hold is given by:

$$
\begin{aligned}
& B_{t+1}+\boldsymbol{P}_{t}\left(C_{t}+I_{k, t}+I_{h, t}\right)+\boldsymbol{P}_{t}^{h} H_{t}^{m}+\boldsymbol{P}_{t}^{s} S_{t+1} \\
+ & \frac{\phi_{b}}{2}\left(\frac{B_{t+1}}{\boldsymbol{P}_{1 t} \frac{Y_{t}}{n}}-b\right)^{2} \boldsymbol{P}_{1 t} \frac{Y_{t}}{n}+\frac{\phi_{s}}{2}\left(S_{t+1}-S\right)^{2} \\
= & R_{t-1} B_{t}+\boldsymbol{P}_{t}^{s}\left(S_{t}+D_{t}\right)+\boldsymbol{W}_{t} L_{t}+R_{t}^{k} K_{t},
\end{aligned}
$$

where $B_{t+1}$ is a riskless one-period nominal bond, bought in period $t$ and maturing in period $t+1 ; \boldsymbol{P}_{t}^{h}$ is the nominal housing price. $R_{t}$ is the gross nominal interest rate on the riskless bond. To facilitate comparison with the previous literature, we focus on the interactions between asset prices and the monetary policy at the aggregate level, and not the individual firm level. Specifically, we assume that there is a mutual fund that owns all the firms in whole economy. $S_{t+1}\left(S_{t}^{*}\right)$ is the amount of mutual fund bought by the representative household in region $1(2) . \boldsymbol{P}_{t}^{s}$ is the nominal price of a unit of the stock of the mutual fund. $D_{t}$ is the dividend paid by the mutual fund, whose determination will be explained later. The term $\frac{\phi_{b}}{2}\left(\frac{B_{t+1}}{\boldsymbol{P}_{1 t} \frac{Y_{t}}{n}}-b\right)^{2} \boldsymbol{P}_{1 t} \frac{Y_{t}}{n}$ and $\frac{\phi_{s}}{2}\left(S_{t+1}-S\right)^{2}$ are (quadratic) adjustment cost for bond holding and stock holding respectively. These are simple device to capture the idea of transaction cost in financial market trading.

Substituting $I_{k, t}$ and $I_{h, t}$ from equations (24) and (25) into the budget constraint (26), the representative household's optimization problem consists of choosing $C_{t}, B_{t+1}, L_{t}, K_{t+1}$, $H_{t+1}, H_{t}^{m}$ and $S_{t+1}$ to maximize the intertemporal utility, (21), subject to the budget constraint (26). The first order conditions with respect to $C_{t}, B_{t}, L_{t}, K_{t+1}, H_{t+1}, H_{t}^{m}$ and $S_{t+1}$ are:

$$
\begin{gathered}
\frac{1}{C_{t}^{\sigma}}=\Lambda_{t} \boldsymbol{P}_{t} \\
\Lambda_{t}\left(1+\phi_{b}\left(\frac{B_{t+1}}{\boldsymbol{P}_{1 t} \frac{Y_{t}}{n}}-b\right)\right)=\beta E_{t} \Lambda_{t+1} R_{t},
\end{gathered}
$$




$$
\begin{aligned}
& \gamma_{l} L_{t}^{\xi}=\Lambda_{t} W_{t} \\
& \beta E_{t} \Lambda_{t+1} R_{t+1}^{k}+\beta E_{t} \Lambda_{t+1} \boldsymbol{P}_{t+1}\left[\left(1-\delta_{k}\right)+\phi_{k} \frac{K_{t+2}-K_{t+1}}{K_{t+1}}+\frac{\phi_{k}}{2} \frac{\left(K_{t+2}-K_{t+1}\right)^{2}}{K_{t+1}^{2}}\right] \\
& =\Lambda_{t} \boldsymbol{P}_{t}\left(1+\phi_{k} \frac{K_{t+1}-K_{t}}{K_{t}}\right) \\
& \gamma_{h} \beta E_{t} \frac{1}{H_{t+1}^{\omega_{h}}}+\beta E_{t} \Lambda_{t+1} \boldsymbol{P}_{t+1}\left[\left(1-\delta_{h}\right)+\phi_{h} \frac{H_{t+2}-H_{t+1}}{H_{t+1}}+\frac{\phi_{h}}{2} \frac{\left(H_{t+2}-H_{t+1}\right)^{2}}{H_{t+1}^{2}}\right] \\
& =\Lambda_{t} \boldsymbol{P}_{t}\left(1+\phi_{h} \frac{H_{t+1}-H_{t}}{H_{t}}\right) \text {, } \\
& \boldsymbol{P}_{t}^{h}=\boldsymbol{P}_{t}\left[\left(1-\delta_{h}\right)+\phi_{h} \frac{\left(H_{t+1}-\left(H_{t}+H_{t}^{m}\right)\right)}{H_{t}+H_{t}^{m}}+\frac{\phi_{h}}{2} \frac{\left(H_{t+1}-\left(H_{t}+H_{t}^{m}\right)\right)^{2}}{\left(H_{t}+H_{t}^{m}\right)^{2}}\right], \\
& \Lambda_{t}\left(\boldsymbol{P}_{t}^{s}+\phi_{s}\left(S_{t+1}-S\right)\right)=\beta E_{t}\left[\Lambda_{t+1}\left(\boldsymbol{P}_{t+1}^{s}+D_{t+1}\right)\right]
\end{aligned}
$$

where $\Lambda_{t}$ is the Lagrangian multiplier associated with the budget constraint, (26). Equation (27) relates $\Lambda_{t}$ to the marginal utility of consumption. Equation (28) is the bond Euler equation. Equation (29) equates the marginal benefit and cost of labor hour. Equations (30) and (30) are the Euler equations for physical capital and housing stock, respectively. Equations (31) and (33) are the pricing equations for housing and stock, respectively. If the portfolio adjustment cost is zero, $\phi_{s}=0$, and imposing the no bubble condition $\lim _{j \rightarrow \infty} E_{t}\left[\sum_{j=0}^{\infty} \beta^{j} \Lambda_{t+j} \boldsymbol{P}_{t+j}^{s}\right]=0$, then (33) is reduced to the familiar asset price equation, which states that the stock price is the discounted value of all future dividend weighted by the pricing kernel $\beta^{j} \frac{\Lambda_{t+j}}{\Lambda_{t}}$ and in expected value terms,

$$
\boldsymbol{P}_{t}^{s}=E_{t}\left[\sum_{j=0}^{\infty} \beta^{j} \frac{\Lambda_{t+j}}{\Lambda_{t}}\left(D_{t+j}\right)\right]
$$


Thus, (33) can be interpreted as a generalization of (34).

\subsection{Market clearing and aggregation}

The market clearing conditions are standard and we simply extend their formulation in a multi-regional setting here. First, the total net supply of bonds is zero in equilibrium:

$$
n B_{t}+(1-n) B_{t}^{*}=0
$$

The households from the two regions hold all the equity in equilibrium:

$$
n S_{t}+(1-n) S_{t}^{*}=1
$$

There is also no net trade in housing stock in each region:

$$
H_{t}^{m}=0
$$

The total demand of business capital and labor inputs across all firms must equal their supply:

$$
\begin{aligned}
& \int_{0}^{n} K_{t}(i) d i=n K_{t}, \\
& \int_{0}^{n} L_{t}(i) d i=n L_{t} .
\end{aligned}
$$

The supply of final goods needs to equal its demand. The case for region 1 is as follows:

$$
Z_{t}=n\left(C_{t}+I_{k, t}+I_{h, t}+\frac{\phi_{b}}{2}\left(\frac{B_{t+1}}{\boldsymbol{P}_{1 t \frac{Y_{t}}{n}}}-b\right)^{2} \boldsymbol{P}_{1 t} \frac{Y_{t}}{n}+\frac{\phi_{s}}{2}\left(S_{t+1}-S\right)^{2}\right)
$$


and there is an analogous one in the region 2. Making use of the three equilibrium conditions above, and the equilibrium condition that the ratio of factor inputs is equalized across firms because of the Cobb-Douglas production function, equations (17) to (18) can be aggregated as:

$$
\begin{aligned}
R_{t}^{k} & =\theta M C_{t} A_{t}\left(K_{t}\right)^{\theta-1}\left(L_{t}^{d}\right)^{1-\theta} \\
\boldsymbol{W}_{t} & =(1-\theta) M C_{t} A_{t}\left(K_{t}\right)^{\theta}\left(L_{t}^{d}\right)^{-\theta} .
\end{aligned}
$$

The random probability of adjusting prices allows us to write their price index, equations (9), as:

$$
\boldsymbol{P}_{1, t}=\alpha_{y}\left(\Pi \boldsymbol{P}_{1, t-1}\right)^{1-\eta_{y}}+\left(1-\alpha_{y}\right)\left(\tilde{\boldsymbol{P}}_{1, t}\right)^{1-\eta_{y}}
$$

In equilibrium, equation (16) holds with equality. Combining equations (13) and (16) and aggregating the resulting equation across firms, we have:18

$$
n A_{t}\left(K_{t}\right)^{\theta}\left(L_{t}^{d}\right)^{1-\theta}=s_{y, t} Y_{t}
$$

where

$$
s_{y, t} \equiv \int_{0}^{1}\left(\frac{\boldsymbol{P}_{1, t}(i)}{\boldsymbol{P}_{1, t}}\right)^{-\eta_{y}} d i .
$$

As noted in Schmitt-Grohé and Uribe (2006, 2007) and Khan et al. (2003), $s_{y, t}$ is a measure of the resource cost of price dispersion associated with the Calvo-style price setting, and it can be shown that $s_{y, t} \geq 1$. Higher values of $s_{y, t}$ correspond to a higher resource cost of price dispersion, as a given combination of total capital and labor inputs gives rise to a smaller amount of aggregate output, $Y_{t}$. Similar to the case of the price index, given the

\footnotetext{
${ }^{18}$ In the equation below, we have made use of the fact that ratio of factor inputs is identical across firms in this model.
} 
random nature of price adjustments, $s_{y, t}$ can be written recursively as:

$$
s_{y, t}=\alpha_{y}\left(\Pi \frac{\boldsymbol{P}_{1, t-1}}{\boldsymbol{P}_{1, t}}\right)^{-\eta_{y}} s_{y, t-1}+\left(1-\alpha_{y}\right)\left(\frac{\tilde{\boldsymbol{P}}_{t}}{\boldsymbol{P}_{1, t}}\right)^{-\eta_{y}} .
$$

Finally, it is assumed that all profits are distributed as dividend, so the nominal dividend $D_{t}$ equals:

$D_{t} \equiv \int_{0}^{n}\left(\boldsymbol{P}_{1, t}(i) Y_{t}(i)-R_{t}^{k} K_{t}(i)-\boldsymbol{W}_{t} L_{t}(i)\right) d i+\int_{1-n}^{1}\left(\boldsymbol{P}_{2, t}(i) Y_{t}^{*}(i)-R_{t}^{k *} K_{t}^{*}(i)-\boldsymbol{W}_{t}^{*} L_{t}^{*}(i)\right) d i$

\subsection{Monetary policy}

We assume that the consolidated government conducts monetary policy using a Taylor (1993)-style feedback rule. We assume that the consolidated government reacts to aggregate inflation rate, constructed from weighted average of region specific inflation rates, with the weights being the population sizes of the regions, as well as to the GDP.

$$
\ln \left(R_{t} / R\right)=\Gamma_{p}\left(n \ln \left(\Pi_{t} / \Pi\right)+(1-n) \ln \left(\Pi_{t}^{*} / \Pi^{*}\right)\right)+\Gamma_{y} \ln \left(G D P_{t} / G D P\right)+\varepsilon_{t}^{R},
$$

where $G D P_{t}$ is the current period national output, where $G D P$ is the steady state national output (all in real terms). Since the focus of this paper is on asset prices, we assume that reaction coefficients $\Gamma_{p}=1.5, \Gamma_{y}=0.125$, i.e. they take on the values that Taylor (1993) finds to describe US economy rather well. ${ }^{19} \varepsilon_{t}^{R}$ is an i.i.d shock, with a standard deviation of $\sigma_{\varepsilon^{R}}$, that captures deviation from the Taylor rule and can be interpreted as a monetary

\footnotetext{
${ }^{19}$ Taylor (1993) reports a value of 0.5 on annualized GDP, which translate into a value of 0.125 on quarterly GDP.
} 
policy shock.

\section{Solution method and calibration}

We solve the model by taking first-order Taylor approximations of the equations around a deterministic steady state. As in most DSGE models, the model is calibrated to match certain stylized facts of the US economy in a quarterly frequency. For the benchmark case, we calibrate the model so that (1) region 1 and region 2 are symmetric, except for their housing adjustment cost parameters, and (2) the two regions share some characteristics with the aggregate US economy in the data. Since we assume that the two regions are symmetric, the population size of region $1, n$, is set to 0.5 . The subjective discount factor, $\beta$, is set to 0.99 , as is commonly assumed in the literature. The coefficient of relative risk aversion for consumption $\sigma$, the coefficient of relative risk aversion for housing $\omega_{h}$, and the inverse of Frisch labor elasticity $\xi$ are all set to unity. In other words, the periodic utility function reduces to a "semi-log" form. The preference parameter for labor in the utility function, $\gamma_{l}$ is calibrated so that households spend $20 \%$ of their time working in the steady state. The preference parameter for housing in the utility function, $\gamma_{h}$ is calibrated so that the steady state ratio of housing investment to consumption is $0.074 .^{20}$ Following the literature of two-country model of international business cycles, the elasticities of substitution of goods from regions 1 and 2 in the final goods, $\varrho$, is set to 3 . It is somewhat higher than the usual figure of 1.5, as the elasticity of substitution of goods between regions should be higher than among countries, due to a variety of reasons, including trade barriers, transportation cost, etc. ${ }^{21}$ The shares of region 1's goods in the final goods of the two regions in the steady state, $\varpi$ and $\varpi^{*}$ are calibrated so that there is "home-biasedness" in the (regional) production of

\footnotetext{
${ }^{20}$ This steady state ratio comes from Davis and Heathcote (2005), who report that residential investment is $4.7 \%$ of GDP, while consumption is $63.8 \%$ of GDP on average.

${ }^{21}$ We also check the impulse responses and find that under this elasticity of substitution, the impulse response functions are all reasonable and resemble to those in the literature.
} 
the final goods. Specifically, we assume that each region uses more of its own goods in the production of the final goods. Note that this assumption is necessary in order that the price inflation rates in the two regions are different. We set $\varpi=1-\psi(1-n)$ and $\varpi^{*}=\psi n$, so that the share of goods from the other region in the final goods equals the product of $\psi \in[0,1]$, and the size of the other region. The parameter $\psi$ can be interpreted as the degree of openness among the two regions. For $\psi=1$, the share of goods from the other region in the final goods equals the size of the other region. For $\psi=0$, each region consumes only goods from its own region. In the benchmark model, we will set $\psi$ to 0.5 , so that $\varpi=0.75$ and $\varpi^{*}=0.25$ respectively. The steady state bond to output ratio, $b$, is set to zero while the steady state stock holding $S$ is set to 1 .

The share of capital in production, $\theta$ is set to 0.3 , as is commonly assumed in the literature. The depreciation rates of capital and housing stock, $\delta_{k}$ and $\delta_{h}$, are set to 0.014 and 0.004, respectively, following Davis and Heathcote (2005). ${ }^{22}$ The capital adjustment cost parameter and the region 1's housing adjustment cost parameter, $\phi_{k}$ and $\phi_{h}$, are set so that the standard deviations of capital investment and housing investment are approximately 4.4 and 5.4 times the standard deviation of output, respectively. ${ }^{23}$ Region 2's capital adjustment cost parameter, $\phi_{k}^{*}$, is the same as $\phi_{k}$. Since we intend to investigate the effects of asymmetry in housing adjustment cost parameters, once we find $\phi_{h}$, we set $\phi_{h}^{*}=10 \phi_{h}$, so that region 2 has higher housing adjustment cost than region 1 . In practice, such difference in adjustment costs can be due not only to physical or engineering reason (Saiz, 2010), but also to political economy reason. For instance, the residents may vote to limit the number of new permits and hence constrain how fast the city can "grow." Residents can also vote for zoning, which demands a minimum size for houses within the neighborhood. Clearly, it will limit the number of housing units to be supplied in the market. In some cities, homeowners are

\footnotetext{
${ }^{22}$ Specifically, we convert the annual depreciation rates in Davis and Heathcote (2005) to quarterly values.

${ }^{23}$ This is to be consistent with the ratios of the standard deviations capital investment and housing investment to the standard deviation of output in the data.
} 
required to collect signatures from others in the neighborhood in order to build an additional structure on top of existing ones. Thus, the residents can collective limit the "new supply" of housing units (for more details, see Glaeser, Gyourko and Saks, 2005a, b; Ortalo-Magne and Prat, 2007; among others). Perhaps more importantly, Saiz (2010) finds that anti-growth local land policies are more likely to arise in growing, land-constrained metropolitan areas. Econometrically, Saiz (2010) finds that supply elasticities can be well-characterized as functions of both physical and regulatory constraints. To maintain the model tractability and to capture the effect that some regions have higher supply elasticities than the others, we find that (artificially) increase $\phi_{h}^{*}$ (relative to $\phi_{h}$ ) seems to be a convenient way in modeling and hence enabling us to focus on the macroeconomic implications of such differences.

The elasticity of substitution across different varieties of goods, $\eta_{y}$, is set to 7.66 , so that the steady state markup of prices over marginal cost is $15 \%$, following Rotemberg and Woodford (1998). The fraction of firms not setting price optimally each quarter, $\alpha_{y}$, is set to 0.75, following Canzoneri et al. (2005), which implies average price duration of 4 quarters. Following the literature, we set the steady state gross inflation rate, $\pi$, to 1 . Finally, we need to set the persistence and standard deviation of the region-specific technology shocks, $\rho^{A}$ and $\sigma_{\varepsilon^{A}}$. We set them to 0.95 and 0.009 , respectively, following the national estimate by Cho and Cooley (1995). We do that for two reasons. First, we are not aware of systematic estimates along this line. Second, we can compare our results easily with the literature. In particular, if we put $n$ to be arbitrarily close to unity, our model is reduced to the standard DSGE model. This provides us an additional way to verify our model and computer program. The standard deviation of monetary policy shock, $\sigma_{\varepsilon^{R}}$ is set to 0.007 . This is the standard deviation of the residual when the Taylor rule (48) is fitted to the interest rate data. As a preliminary step, we study an environment with constant volatility of housing price. Miller and Peng (2006) find evidence of the time-varying volatility in only $17 \%$ of the 277 metropolitan areas (MSA), 
suggesting that empirically, the housing price volatility is relatively "stable." 24 Finally, the adjustment cost parameters for bond and stock, $\phi_{b}$ and $\phi_{s}$, are both set at a small value of 0.001. ${ }^{25}$ This is necessary to ensure the stationarity of the model, so that a bounded solution to the model can be computed. Table 2 summarizes the benchmark parameterization.

(Table 2 about here)

\section{Results}

Tables 3 and 4 summarize the basic numerical results. Recall that the only ex-ante difference between regions 1 and 2 is the housing adjustment costs. Thus, it is not surprising that the aggregate volatility of the physical capital investment (relative to the output) is about the same in both regions. On the other hand, the volatility of the housing investment in region 2 (relative to the regional output $Y_{t}^{*}$ ) is much lower than the counterparts in the aggregate and that in the region 1 . The mirror image of this result can be found in the relative volatility of the house price. In region 1, since the housing adjustment cost is much lower, the volatility of the housing investment is about 5 times of the corresponding regional output $Y_{t}$. At the same time, the volatility of the house price is only $5 \%$ of the corresponding regional output. In contrast, in region 2 where housing adjustment cost is higher, the volatility of housing investment is only 2.5 times of the corresponding regional output, but the volatility of the house price is $24 \%$ of the regional output. This is broadly consistent with the stylized facts that we highlight in the introduction that heterogeneity in house price levels and volatilities are related to housing supply elasticities.

\footnotetext{
${ }^{24}$ Moreover, they find that MSAs with higher prices tend to have higher housing price volatility.

${ }^{25}$ With $\phi_{b}$ and $\phi_{s}$ set at 0.001 , a $1 \%$ deviation of bond and stock from their steady state value will incur an adjustment cost of 0.00000005 unit of goods, which is very small.
} 
This model is also capable to produce other stylized facts, some of them have been documented in Hwang and Quigley (2006). First, the correlation between the national house price $\left(P_{t}^{h, n a t i o n a l}\right)$ and the national GDP is high $(0.64)$, the counterparts between the regional house prices $\left(P_{t}^{h}\right.$ and $\left.P_{t}^{h *}\right)$ and the national GDP is much lower ( 0.51 for region 1 and 0.57 for region 2). Second, for regions 1 and 2, the correlations between the regional housing price and the regional output (i.e. $\operatorname{corr}\left(P_{t}^{h}, Y_{t}\right)$ and $\left.\operatorname{corr}\left(P_{t}^{h *}, Y_{t}^{*}\right)\right)$ are much higher than that between the regional house price and the national GDP (i.e. $\operatorname{corr}\left(P_{t}^{h}, G D P_{t}\right)$ and $\left.\operatorname{corr}\left(P_{t}^{h *}, G D P_{t}\right)\right)$. Third, the correlation between the house price in the high adjustment cost region (region 2 in this paper) and that in the low adjustment cost region (region 1 in this paper) is low (0.25). In addition, Table 4 reproduces the stylized fact that the stock price is close to a unit-root process. It also shows that the serial correlation of the house price in low adjustment cost region is lower. Notice that in region 1 , the correlation between the contemporary house price and the 4-quarters lag is only 0.88 , while the counterpart in region 2 is 0.95 , which is much more persistent.

\section{(Table 3, 4 about here)}

Table 5 summarizes the correlations between the (national) stock price and different house prices. It is obvious that the correlation between the stock price and the regional house prices in region 1 are very different from those in region 2. The intuition is simple. When the housing adjustment cost is low, the housing supply can quickly respond to shocks, and hence the house price will be less correlated to the national output as well as the stock price, which is the discounted sum of firm profit in expected value. In fact, Table 3 shows that the correlation between region 1 house price and the national GDP is only 0.51, which is smaller than the counterpart in region $2(0.57)$. Correspondingly, Table 5 shows that the correlation between the region 1 house price and the contemporary period stock price is 0.46, which is significantly lower than that in region 2 (0.65). An implication is that agents 
living in region 1 have higher incentives to purchase stock, as their (location-specific) housing wealth is less correlated with the national stock price. In other words, the optimal portfolio may be region-specific.

\section{(Table 5 about here)}

To gain more intuitions on how the model works, Figure 2 presents the impulse responses of different variables when the system is impacted by a $1 \%$ technology shock from region 1 (i.e., a one-time increase in $\varepsilon_{t}^{A}$ in region 1 , the size of which is $1 \%$ of the steady state of $\left.A_{t}\right),{ }^{26}$ and Figure 3 presents the counterpart when the system is impacted by a $1 \%$ technology shock from the region 2 . The results are intuitive. When the productivity shock occurs in the region 1 , the physical capital investment in region 1 should increase to take advantage of that temporary shock. The effect is so strong that the capital investment in region 2 and the housing investment in region 1 actually decrease. Resources are reallocated across regions as well as sectors, from the less productive ones to the more productive one. At the same time, output in region 1 increases. As the output in region 1 continues to increase, the house price in region 1 eventually increases as well. Such increase in the region 1 house price obviously will stimulate even more housing investment in region 1 . Notice that even the region 2 house price increases. It is because agents in region 2 also share the benefit of the positive shock from region 1 through the stock market, which increases more than the national house price index in terms of percentage deviation from the steady state after the shock. The housing investment in region 2, however, almost remains unchanged. The high adjustment cost discourages the region 2 to increase their housing investment.

(Figure 2 about here)

\footnotetext{
${ }^{26}$ Note that the shock will lead to a temporary but persistent increase in $A_{t}$ through the autoregressive coefficient $\rho^{A}$.
} 
When the temporary positive shock occurs in region 2 , the physical capital investment in region 2 increases while that in the region 1 decreases. This is simply the mirror image of the previous case when the positive shock occurs in region 1. On the other hand, we notice that the housing investment situation is slightly different. While the region-specific productivity shock leads to an increase in the housing investment in region 2 , it also leads to a decrease in the housing investment in region 1 . This is because the adjustment cost of housing in region 2 is much higher. Since the corresponding adjustment cost in region 1 is much lower, it is cost-efficient to (temporarily) decrease the housing investment in region 1. In subsequent periods, as more output are produced and as agents in region 1 share the benefits of productivity shock through the stock market, the housing investment in region 1 increases. Notice also that in terms of magnitudes, the response of house price in region 2 to a productivity shock from region 2 is greater than the response of house price in region 1 to a productivity shock from region 1. In contrast, the response of housing investment in region 2 to a productivity shock from region 2 is smaller than the response of housing investment in region 1 to a productivity shock from region 1. In sum, the model suggests that, other things being equal, regions with lower adjustment costs will have more volatile housing investments, and regions with higher adjustment costs will have more volatile house prices.

\section{(Figure 3 about here)}

Lastly, we consider an additional exercise, which is a $1 \%$ (contractionary) monetary policy shock (i.e., a one-time increase in $\varepsilon_{t}^{R}$ ). It pushes up the interest rate. As the Figure 4 shows, it has a very short-lived impact on the physical capital investment and output. While the magnitudes of the responses of physical investment and output differ in regions 1 and 2, the differences are very small quantitatively. This should not be surprising as Carlino and Defina $(1998,1999,2006)$ find that it is heterogeneity in industrial structure (such as the 
share of manufacturing industry, the share of small firms, etc.) that drives the regional differences in output responses. On the other hand, Figure 4 clearly shows that the housing investments and house prices behave very differently across regions. As region 2 has a much higher adjustment cost in housing, its change in housing investment is very slow relative to the region 1. As a result, the house price in region 2 displays more volatility. This is consistent with the finding of Fratanoni and Schuh (2003) that regional housing market display heterogeneous response to monetary policy. Hence, our model is consistent with the findings in both Carlino and Defina (1998, 1999, 2006) concerning output responses, and Fratanoni and Schuh (2003) concerning housing market responses, among other previous empirical research.

(Figure 4 about here)

\section{Concluding Remarks}

There is a growing empirical literature on the regional difference as well as regional comovement. Theoretical works are, however, relatively rare. This paper takes a preliminary step in extending a typical DSGE model to incorporate regional considerations. The model is calibrated to match the U.S. economy in several dimensions and numerical results are generated. First, our model is consistent with the stylized fact that with lower housing supply elasticity, both the level and volatility of the house price will be higher. We are also able to generate heterogeneous regional housing market responses to monetary shock though we find that heterogeneity in housing supply elasticities alone is not enough to explain heterogeneous responses of regional output to monetary policy shock. Thus, we reproduce the empirical findings for both Carlino and Defina (1998, 1999, 2006), and Fratanoni and Schuh (2003). In a sense, we also confirm the observation that the housing market seems to be 
more vulnerable to monetary shocks compared to output.

Moreover, we find that differences between the national variable and its regional counterpart can be very significant. For instance, while the national housing price is highly correlated to the national GDP, the housing price in some region needs not be. While the national housing price is highly persistent, the regional counterparts need not be. In general, the correlation between the regional housing price and the regional output is stronger than the counterpart between the regional housing price and the national GDP.

In terms of the asset prices, this model successfully reproduces the near-unit-root behavior of the stock price. While the housing prices in both national and regional levels are also positively and serially correlated, there are regional differences. This model predicts that regions with lower housing adjustment costs would tend to have lower serial correlations. This model also predicts that the regions with lower housing adjustment costs will display much lower correlations with the national stock price, suggesting that the optimal portfolio can be region-specific. While some of these results have been documented before, some are awaiting further empirical confirmations. We hope that future empirical works will verify the testable implications delivered in this paper.

This paper can be, and should be extended in other ways. For instance, for simplicity, we have assumed that the regions are ex-ante identical except for the housing adjustment cost. In practice, regions can differ in many dimensions. For instance, growth management or other forms of new supply restrictions seem to occur more frequently in areas with fastgrowing housing price and economic output. In addition, different regions tend to specialize in different sectors, and hence will have different volatility in income. For instance, some regions may be more export-dependent, and hence are exposed to exchange rate risk, while some tend to mainly serve customers within the same country. The output in some regions may be more tied to some natural resources (such as oil or metal) or agricultural products. Their income would be more volatile than those that are not. Future work should incorporate 
such asymmetries as well. The model has also assumed a representative agent in each region. In practice, heterogeneity among agents, such as in the form of income inequality, is important. The heterogeneity among agents may also call for very different policies in a political economy context. This will significantly enrich the current framework. Open economy considerations such as the foreign capital flow or regional trade exposure should also be explored. 


\section{References}

[1] Baxter, M., Jermann, U., King, R. G., 1998. Nontraded Goods, Nontraded Factors, and International Non-diversification, Journal of International Economics, 44(2), 211-29.

[2] Berliant, M. and F. C. Kung, 2009. Bifurcation in regional migration dynamics, Regional Science and Urban Economics, 39 (6), 714-720.

[3] Calvo, G.A., 1983. Staggered prices in a utility-maximizing framework. Journal of Monetary Economics 12, 383-398.

[4] Canzoneri, M.B., Cumby, R.E., Diba, B.T., 2005. Price and wage inflation targeting: variations on a theme by Erceg, Henderson, and Levin. In: Faust, J., Orphanides, A., Reifschneider, D. (Eds.), Models and Monetary Policy: Research in the Tradition of Dale Henderson, Richard Porter, and Peter Tinsley. Board of Governors of the Federal Reserve System: Washington DC.

[5] Carlino, G., Defina, R., 1998. The differential regional effects of monetary policy. Review of Economics and Statistics 80, 572-587.

[6] Carlino, G., Defina, R., 1999. The differential regional effects of monetary policy: evidence from the U.S. states. Journal of Regional Science 39, 339-358.

[7] Carlino, G., Defina, R., 2006. Macroeconomic Analysis using regional data: an application to monetary policy. In: R. Arnott and D. McMillen (Eds.), A Companion to Urban Economics, Oxford: Blackwell.

[8] Cho, J.O., Cooley T.F, 1995. The business cycle with nominal contracts. Economic Theory 6, 13-33.

[9] Christiano, L.J., Eichenbaum M., Evans C., 2005. Nominal rigidities and the dynamic effects of a shock to monetary policy. Journal of Political Economy 113(1), 1-45.

[10] Christiano, L. J., M. Trabandt and K. Walentin, 2010. DSGE Models for Monetary Policy Analysis, forthcoming in Handbook of Monetary Economics, vol. 3.

[11] Davis, M. and J. Heathcote (2005), "Housing and the business cycle," International Economic Review, 46(3), 751-784.

[12] Epple, D., Nechyba, T., 2004. Fiscal Decentralization. In: J. V. Henderson and J. F. Thisse (Eds.), Handbook of Regional and Urban Economics, Vol. 4, New York: Elsevier.

[13] Evans, P. 2000. Income dynamics in regions and countries. In: G. Hess and E. V. Wincoop (Eds.), Intranational Macroeconomics, Cambridge: Cambridge University Press.

[14] Fratantoni, M., Schuh, S., 2003. Monetary policy, housing, and heterogeneous regional markets, Journal of Money, Credit and Banking 35(4), 557-589.

[15] Fu, D. 2007. National, regional and metro-specific factors of the U.S. housing market, Federal Reserve Bank of Dallas, mimeo. 
[16] Glaeser, E.; Gyourko, J. and Saks, R. 2005a. Why Is Manhattan So Expensive? Regulation and the Rise in House Prices. Journal of Law and Economics 48(2), 331-370.

[17] Glaeser, E.; Gyourko, J. and Saks, R. 2005b. Why Have Housing Prices Gone Up? American Economic Review Papers and Proceedings 95(2), 329-333.

[18] Goetzmann, W. N., Massa, M., Simonov, A. 2004. Portfolio Diversification and City Agglomeration. NBER Working Paper No. 10343.

[19] Green, R., Malpezzi, S., Mayo, S. 2005. Metropolitan-specific estimates of the price elasticity of supply of housing, and their sources. American Economic Review 95(2), 334-339.

[20] Greenwood, J., Hercowitz, Z., 1991. The allocation of capital and time over the business cycle, Journal of Political Economy, 99, 1188-1214.

[21] Hwang, M., Quigley, J. M. 2006. Economic fundamentals in local housing markets: evidence from U.S. metropolitan regions. Journal of Regional Science 46(3), 425-453.

[22] Jermann, U., 1998. Asset Pricing in Production Economies. Journal of Monetary Economics, 41(2), 257-75.

[23] Jermann, U., 2002. International Portfolio Diversification and Endogenous Labor Supply Choice. European Economic Review, 46(3), 507-22.

[24] Jermann, U., 2006. The Equity Premium Implied by Production. NBER Working Paper 12487.

[25] Khan, A., King, R.G., Wolman, A., 2003. Optimal monetary policy. Review of Economic Studies 70, 825-860.

[26] Kohler, M., Smith, K., 2005. Housing and the household wealth portfolio: the role of location, Reserve Bank of Australia, mimeo.

[27] Leung, C. K. Y., 2004. Macroeconomics and Housing: a review of the literature. Journal of Housing Economics, 13, 249-267.

[28] Miller, N., Peng, L., 2006. Exploring Metropolitan Housing Price Volatility, Journal of Real Estate Finance and Economics 33, 5-18.

[29] Ortalo-Magne, F., Prat, A., 2007. The political economy of housing supply. University of Wisconsin (Madison) and London School of Economics, mimeo.

[30] Rotemberg, J., Woodford, M., 1998. An Optimization-Based Econometric Framework for the Evaluation of Monetary Policy: Expanded Version. NBER Technical Working Papers 0233.

[31] Saiz, A. 2010. The Geographic Determinants of Housing Supply, Quarterly Journal of Economics, forthcoming. 
[32] Schmitt-Grohé, S., Uribe, M., 2006. Optimal fiscal and monetary policy in a medium scale macroeconomic model. In: Gertler, G., Rogoff, K. (Eds.), NBER Macroeconomics Annual 2005. MIT Press, Cambridge, MA, London, pp. 383-425.

[33] Schmitt-Grohé, S., Uribe, M., 2007. Optimal simple and implementable monetary and fiscal rules. Journal of Monetary Economics 54, 1702-1725.

[34] Taylor, J., 1993. Discretion versus policy rules in practice. Carnegie-Rochester Conference Series on Public Policy 39, 195-214.

[35] Tesar, L., 1993. International Risk Sharing and Non-traded Goods, Journal of International Economics, 35(1-2), 69-89.

[36] Tesar, L., Werner, I. M., 1995. Home Bias and High Turnover, Journal of International Money and Finance, 14(4), 467-92.

[37] Wheaton, W., Simonton, W. 2007. The secular and cyclic behavior of "true" construction costs. Journal of Real Estate Research, 29, 1-25.

[38] Woodford, M., 2003. Interest and prices: foundations of a theory of monetary policy. Princeton University Press, Princeton.

[39] Woodford, M., 2010. Optimal Monetary Stabilization Policy, forthcoming in Handbook of Monetary Economics, vol. 3. 
Table 1

Price elasticity of housing supply and volatility of real house price

\begin{tabular}{lrr} 
Metropolitan areas & $\begin{array}{c}\text { Supply } \\
\text { elasticity }\end{array}$ & $\begin{array}{c}\text { Std. dev. of real } \\
\text { house price }(\%)\end{array}$ \\
\hline Miami & 0.60 & 12.66 \\
Los Angeles-Long Beach & 0.63 & 11.45 \\
San Francisco & 0.66 & 6.51 \\
San Diego & 0.67 & 10.54 \\
New York & 0.76 & 6.20 \\
Chicago & 0.81 & 5.48 \\
Boston-Worcester-Lawrence-Lowell-Brockton & 0.86 & 4.81 \\
Seattle-Bellevue-Everett & 0.88 & 10.49 \\
Cleveland-Lorain-Elyria & 1.02 & 2.66 \\
Portland-Vancouver & 1.07 & 6.47 \\
Detroit & 1.24 & 5.64 \\
Minneapolis-St. Paul & 1.45 & 6.27 \\
Denver & 1.53 & 3.19 \\
Atlanta & 2.55 & 3.39
\end{tabular}


Table 2

Benchmark parameter values

\begin{tabular}{llc}
\hline Parameter & Description & Value \\
\hline$n$ & Size of region 1 & 0.5 \\
$\beta$ & Subjective discount factor & 0.99 \\
$\sigma$ & Coefficient of relative risk aversion & 1 \\
$\omega_{h}$ & Coefficient of relative risk aversion for housing & 1 \\
$\xi$ & Inverse of Frisch labor elasticity & 1 \\
$\varrho$ & Elasticity of substitution between goods from regions 1 and 2 & 3 \\
$\varpi$ & Share of region 1's goods in region 1's final goods & 0.75 \\
$\varpi^{*}$ & Share of region 1's goods in region 2's final goods & 0.25 \\
$\theta$ & Capital share & 0.3 \\
$\delta_{k}$ & Depreciation rate of capital & $0.0557 / 4$ \\
$\delta_{h}$ & Depreciation rate of housing & $0.0157 / 4$ \\
$\phi_{k}$ & Capital adjustment cost & 0 \\
$\phi_{h}$ & Housing adjustment cost for region 1 & 2.5 \\
$\phi_{h}^{*}$ & Housing adjustment cost for region 2 & 25 \\
$\eta_{y}$ & Elasticity of substitution across different variety of goods & 7.66 \\
$\alpha_{y}$ & Fraction of firms not setting price optimally each quarter & 0.75 \\
$\phi_{b}$ & Bond adjustment cost parameter & 0.001 \\
$\phi_{s}$ & Stock adjustment cost parameter & 0.001 \\
$\pi$ & Steady state gross inflation rate & 1 \\
$\rho^{A}$ & Persistence of technology process for region 1 & 0.95 \\
$\rho^{A *}$ & Persistence of technology process for region 2 & 0.95 \\
$\sigma_{\varepsilon^{A}}$ & Standard deviation of technology shock for region 1 & 0.009 \\
$\sigma_{\varepsilon^{A *}}$ & Standard deviation of technology shock for region 2 & 0.009 \\
$\sigma_{\varepsilon^{R}}$ & Standard deviation of monetary policy shock & 0.007 \\
\hline & & \\
& &
\end{tabular}


Table 3

Relative volatility of some national and regional variables and their correlations with the GDP

\begin{tabular}{|c|c|}
\hline $\begin{array}{c}\text { Macro-variables } \\
\text { Relative Volatility }\end{array}$ & \\
\hline $\begin{array}{c}\operatorname{Std}\left(I_{t}^{k, \text { national }}\right) / \operatorname{Std}\left(G D P_{t}\right) \\
\operatorname{Std}\left(I_{t}^{k}\right) / \operatorname{Std}\left(Y_{t}\right) \\
\operatorname{Std}\left(I_{t}^{k *}\right) / \operatorname{Std}\left(Y_{t}^{*}\right) \\
\operatorname{Std}\left(I_{t}^{h, \text { national }}\right) / \operatorname{Std}\left(G D P_{t}\right) \\
\operatorname{Std}\left(I_{t}^{h}\right) / \operatorname{Std}\left(Y_{t}\right) \\
\operatorname{Std}\left(I_{t}^{h *}\right) / \operatorname{Std}\left(Y_{t}^{*}\right) \\
\text { Macro-Asset } \\
\text { Price Relationship }\end{array}$ & $\begin{array}{l}4.38 \\
4.40 \\
4.24 \\
4.17 \\
5.17 \\
2.46\end{array}$ \\
\hline $\begin{array}{c}\operatorname{Std}\left(P_{t}^{s}\right) / \operatorname{Std}\left(G D P_{t}\right) \\
\operatorname{Std}\left(P_{t}^{h, \text { national }}\right) / \operatorname{Std}\left(G D P_{t}\right) \\
\operatorname{Std}\left(P_{t}^{h}\right) / \operatorname{Std}\left(Y_{t}\right) \\
\operatorname{Std}\left(P_{t}^{h *}\right) / \operatorname{Std}\left(Y_{t}^{*}\right) \\
\text { Macro-Asset } \\
\text { Co-movement }\end{array}$ & $\begin{array}{l}0.58 \\
0.17 \\
0.05 \\
0.24\end{array}$ \\
\hline $\begin{array}{c}\operatorname{corr}\left(P_{t}^{s}, G D P_{t}\right) \\
\operatorname{corr}\left(P_{t}^{h, \text { national }}, G D P_{t}\right) \\
\operatorname{corr}\left(P_{t}^{h}, G D P_{t}\right) \\
\operatorname{corr}\left(P_{t}^{h}, Y_{t}\right) \\
\operatorname{corr}\left(P_{t}^{h *}, G D P_{t}\right) \\
\operatorname{corr}\left(P_{t}^{h *}, Y_{t}^{*}\right) \\
\operatorname{corr}\left(P_{t}^{h}, P_{t}^{h *}\right) \\
\end{array}$ & $\begin{array}{l}0.80 \\
0.64 \\
0.51 \\
0.69 \\
0.57 \\
0.79 \\
0.25 \\
\end{array}$ \\
\hline
\end{tabular}


Table 4

Serial correlation of different asset prices

\begin{tabular}{cc}
\hline Stock Price & \\
$\operatorname{corr}\left(P_{t}^{s}, P_{t-1}^{s}\right)$ & 0.99 \\
$\operatorname{corr}\left(P_{t}^{s}, P_{t-2}^{s}\right)$ & 0.97 \\
$\operatorname{corr}\left(P_{t}^{s}, P_{t-3}^{s}\right)$ & 0.95 \\
$\operatorname{corr}\left(P_{t}^{s}, P_{t-4}^{s}\right)$ & 0.94 \\
& \\
House Price & \\
$\operatorname{corr}\left(P_{t}^{h, \text { national }}, P_{t-1}^{h, \text { national }}\right)$ & 0.99 \\
$\operatorname{corr}\left(P_{t}^{h, \text { national }}, P_{t-2}^{h, \text { national }}\right)$ & 0.98 \\
$\operatorname{corr}\left(P_{t}^{h, \text { national }}, P_{t-3}^{h, \text { national }}\right)$ & 0.97 \\
$\operatorname{corr}\left(P_{t}^{h, \text { national }}, P_{t-4}^{h, \text { national }}\right)$ & 0.95 \\
& \\
$\operatorname{corr}\left(P_{t}^{h}, P_{t-1}^{h}\right)$ & 0.98 \\
$\operatorname{corr}\left(P_{t}^{h}, P_{t-2}^{h}\right)$ & 0.95 \\
$\operatorname{corr}\left(P_{t}^{h}, P_{t-3}^{h}\right)$ & 0.92 \\
$\operatorname{corr}\left(P_{t}^{h}, P_{t-4}^{h}\right)$ & 0.88 \\
$\operatorname{corr}\left(P_{t}^{h *}, P_{t-1}^{h *}\right)$ & 0.99 \\
$\operatorname{corr}\left(P_{t}^{h *}, P_{t-2}^{h *}\right)$ & 0.98 \\
$\operatorname{corr}\left(P_{t}^{h *}, P_{t-3}^{h *}\right)$ & 0.97 \\
$\operatorname{corr}\left(P_{t}^{h *}, P_{t-4}^{h *}\right)$ & 0.95 \\
\hline
\end{tabular}


Table 5

Correlation between the stock price and different housing prices

\begin{tabular}{cccc} 
& $\operatorname{corr}\left(P_{t}^{s}, P_{t-j}^{h, \text { national }}\right)$ & $\operatorname{corr}\left(P_{t}^{s}, P_{t-j}^{h}\right)$ & $\operatorname{corr}\left(P_{t}^{s}, P_{t-j}^{h *}\right)$ \\
\hline $\begin{array}{c}\text { (contemporary) } \\
j=0\end{array}$ & 0.70 & 0.46 & 0.65 \\
(lagged house prices) & & & \\
$j=1$ & 0.69 & 0.45 & 0.64 \\
$j=2$ & 0.68 & 0.44 & 0.64 \\
$j=3$ & 0.67 & 0.44 & 0.63 \\
$j=4$ & 0.66 & 0.43 & 0.62 \\
(subsequent house prices) & & & \\
$j=-1$ & 0.70 & 0.48 & 0.65 \\
$j=-2$ & 0.69 & 0.49 & 0.64 \\
$j=-3$ & 0.68 & 0.49 & 0.62 \\
$j=-4$ & 0.66 & 0.48 & 0.61 \\
\hline
\end{tabular}




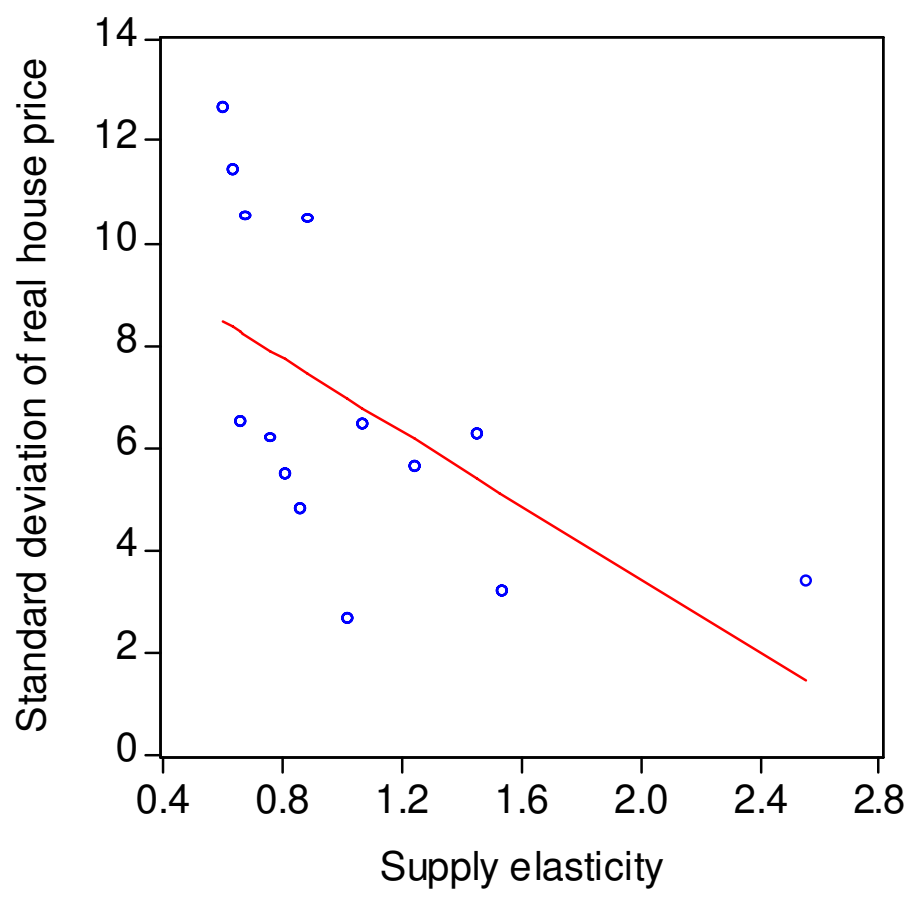

Figure 1: Supply elasticity versus standard deviation of real house price in 14 US metropolitan areas 

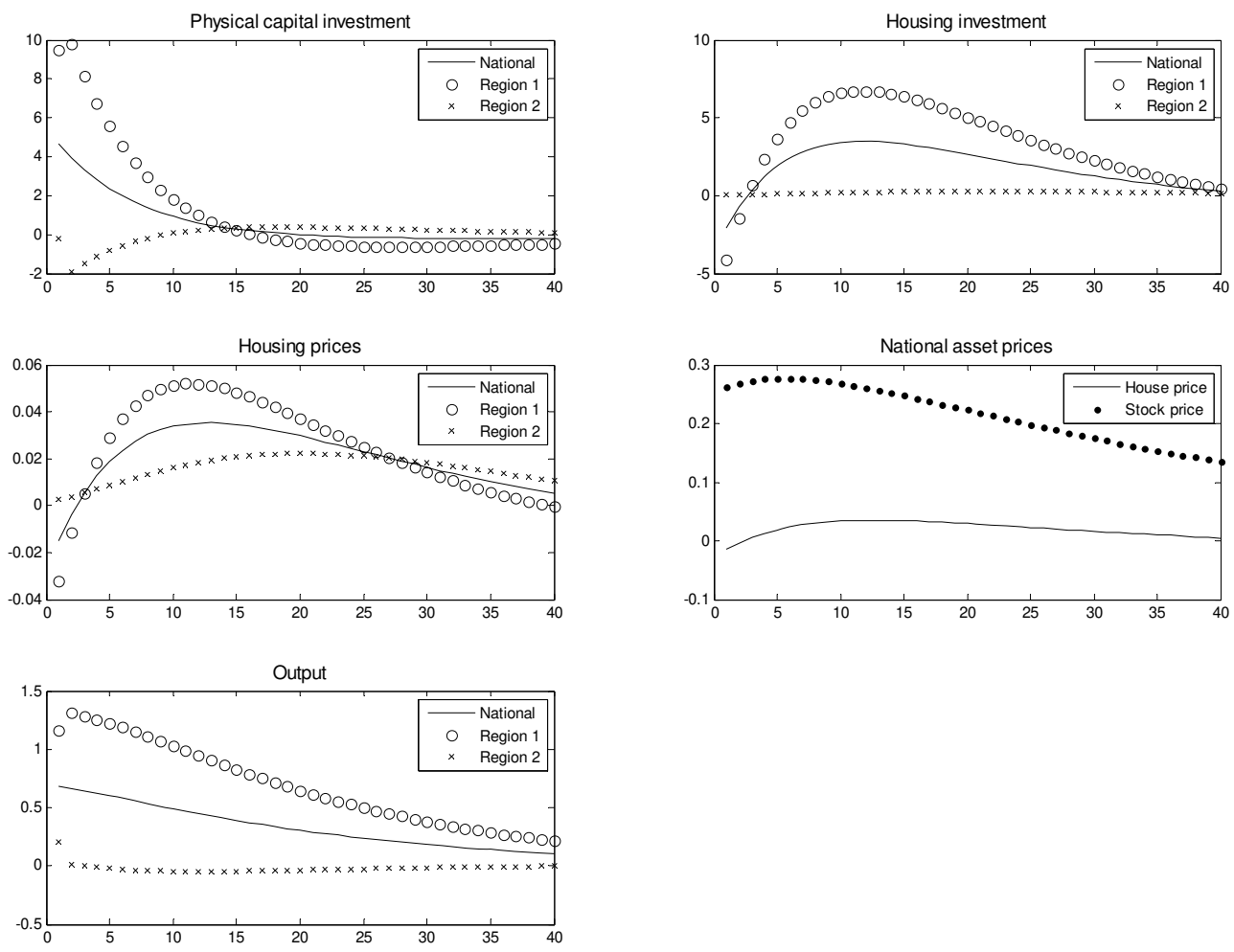

Figure 2: Impulse response to technology shock from region 1 

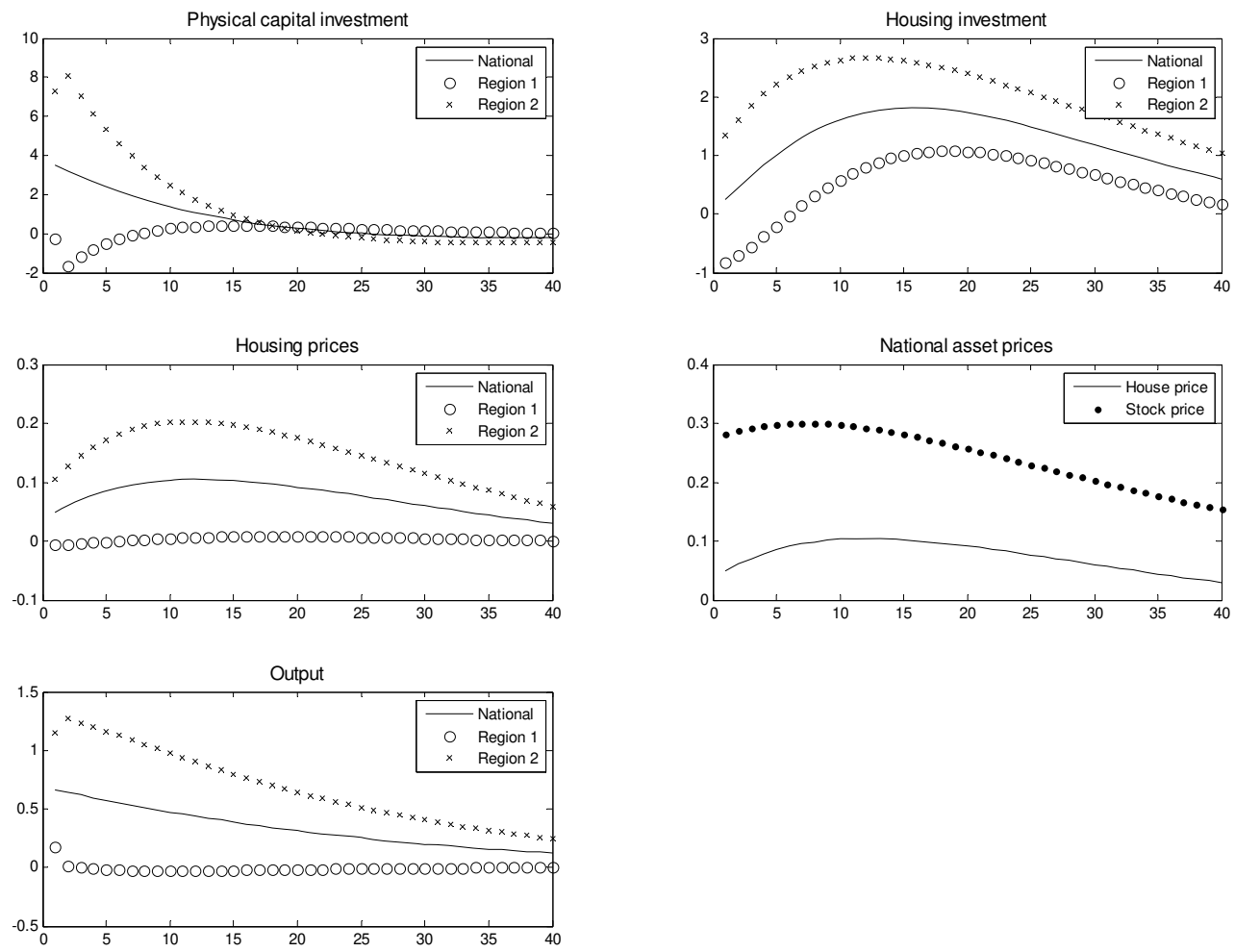

Figure 3: Impulse response to technology shock from region 2 

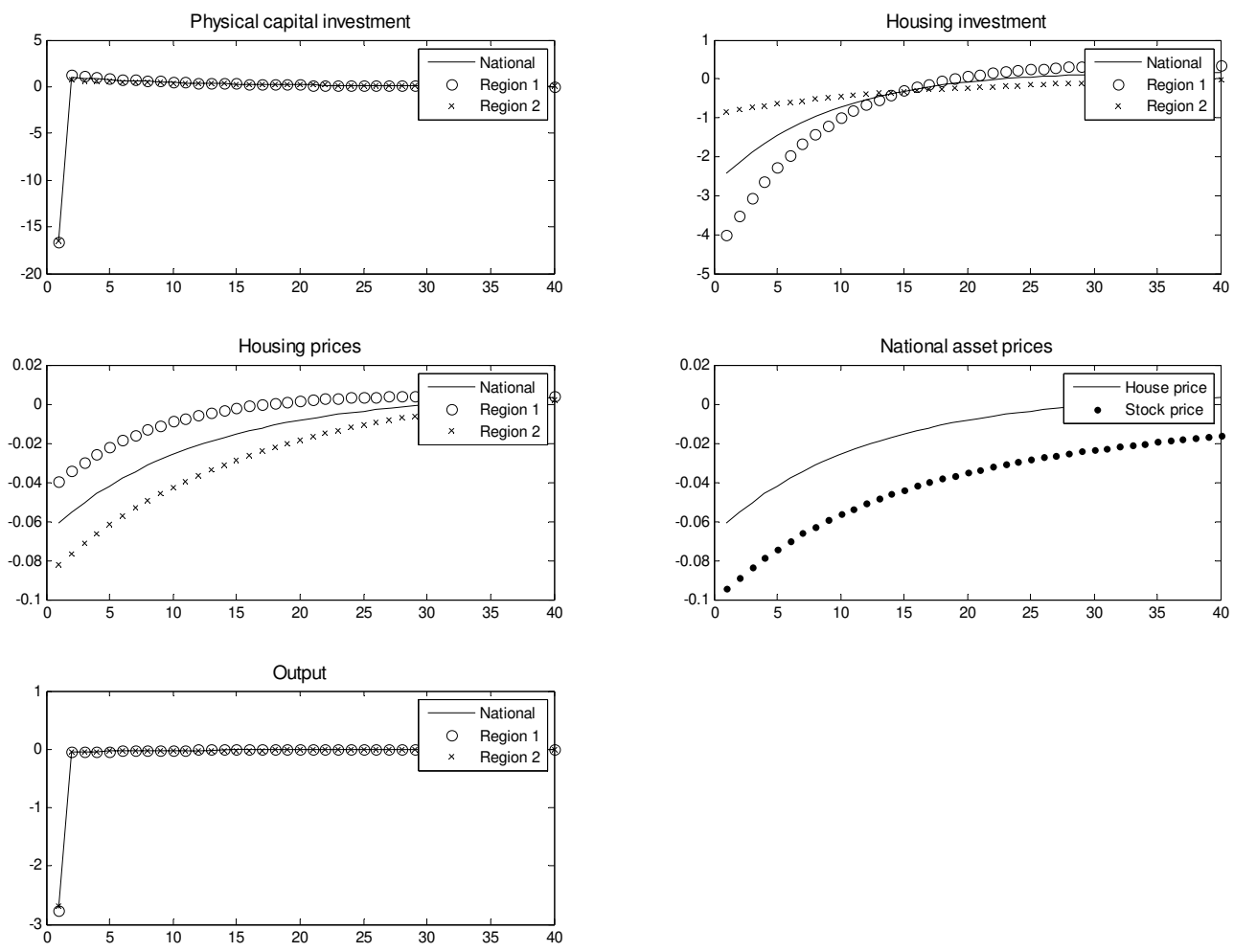

Figure 4: Impulse response to contractionary monetary policy shock 